\title{
A Central Composite Design in increasing the quercetin content in the aqueous onion waste isolates with antifungal and antioxidant properties
}

\author{
Dorota Wianowska $^{1}$ - Małgorzata Olszowy-Tomczyk ${ }^{1} \cdot$ Sylwia Garbaczewska ${ }^{2}$
}

Received: 16 June 2021 / Revised: 21 October 2021 / Accepted: 23 October 2021 / Published online: 5 November 2021

(c) The Author(s) 2021

\begin{abstract}
In this study, to increase the content of quercetin in the isolates obtained from the white and red onion scales, in accordance with the zero waste philosophy, using water as an environmentally and healthy friendly extractant, a mathematical model was constructed, based on the Central Composite Design. The suitability of the model for the accurate and quick study of complex relationships was demonstrated by obtaining a statistically insignificant difference in the yield predicted by the model and that determined experimentally under optimal extraction conditions, i.e., $44.14 \mathrm{mg} / \mathrm{g}(33.57 \mathrm{mg} / \mathrm{g})$ and $45.54 \mathrm{mg} / \mathrm{g}$ $(33.31 \mathrm{mg} / \mathrm{g}$ ) for white (red) onion scales, respectively. To present the obtained isolates applicability, their biological activity was assessed in terms of antioxidant activity and antifungal activity against various fungi, showing properties that are sufficient to encourage the use of this material, previously treated as worthless waste, for the production of various functional ingredients, including functional food additives. Moreover, they can be also used to produce safe and effective protectants meeting the GRAS criteria.
\end{abstract}

Keywords CCD $\cdot$ Agricultural waste $\cdot$ Functional ingredients $\cdot$ Functional food additives $\cdot$ Water extraction $\cdot$ Phenolic compounds

\section{Introduction}

Nowadays, an evident increase in the demand for biologically active natural products and the interest in more ecological and environmentally friendly methods of obtaining them are observed. In accordance with the "zero waste" philosophy, particular attention is paid to the agricultural waste as a new, alternative and cheap source of various functional ingredients of interest for many industries, including the food industry.

Onion (Allium cepa L.) is one of the most cultivated and consumed vegetables in the world. It owes its

Dorota Wianowska

dorota.wianowska@poczta.umcs.lublin.pl

1 Department of Chromatography, Institute of Chemical Sciences, Faculty of Chemistry, Maria Curie-Sklodowska University, Pl. Maria Curie Sklodowska 3, 20-031 Lublin, Poland

2 Department of Synthesis and Technology, Institute of Industrial Organic Chemistry, 6 Annopol St., 03-236 Warsaw, Poland popularity to many health-promoting properties resulting from the presence of phenolic compounds of which quercetin (3,5,7,3', $4^{\prime}$-pentahydroxyflavone) is the most recognizable $[1,2]$. In addition to the free radical scavenging property, quercetin is credited with anti-inflammatory, antihypertensive, anti-bacterial, anti-obesity, antihypercholesterolemic, antiatherosclerotic, and even anti-HIV activities [3,4]. In light of the above, it is not surprising that all possible sources of quercetin, including onion scales as the main and so far treated as worthless waste from the onion cultivation on a global scale, are screened and tested.

Currently various approaches are used to extract quercetin from plants. Among them, there are simple techniques useful on a laboratory scale to assess the actual content of the antioxidant in the plant material $[5,6]$, and more advanced ones, consistent with the principles of green chemistry that can be used in the industrial isolation of natural compounds [7-13]. The latter tend to be more convenient in use, more economical and eco-friendly, rapid as well as sustainable in terms of extraction efficiencies and reproducibility. Their overall positive impact on human is also important as they do not use toxic organic solvents, traces of which might be 
present in the obtained products, making them healthier [14, 15]. One of such techniques is pressure liquid extraction (PLE) also called pressurized hot water extraction (PHWE) or subcritical water extraction (SWE) to emphasize the ecological nature of the applied extractant. Presently, there are numerous studies showing the applicability of this technique for the isolation of various health-promoting compounds from plant material, including quercetin from onion scales $[5,6,8,10,16,17]$. A few of them focus on the possibility of loss of glycoside derivatives of polyphenols under the PHWE conditions [5, 6, 15-17]. Yet, in the case of extraction of quercetin being the aglyconic form of many glycosides, hydrolysis of the latter can be a way of increasing the quercetin content in the obtained extracts and thus promoting the increase of their biological activity.

To verify this in as few experiments as possible, the Central Composite Design (CCD) was used to design the extraction conditions for optimal quercetin yield. A mathematical model was constructed to determine the degree of desirability of a response with respect to the optimal value intended to be achieved, taking into account the extraction affecting variables such as temperature, pressure, and flow velocity of the extraction medium. The designed optimal extraction conditions were verified by comparing the quercetin yield calculated with that obtained during the actual extraction under these conditions. To show the wide range of possible biological activity of the obtained quercetin-rich isolates, they were assessed for antioxidant activity using different approaches as well as antifungal activity against various fungi.

\section{Materials and methods}

\section{Plant material}

The representative portions of white and red onions purchased from a local market were hand peeled to obtain the inedible outer scales of the onion. Sufficiently large samples (approx. $500 \mathrm{~g}$ ) were ground using a Braun cutting mill to a particle size of $0.2-0.4 \mathrm{~mm}$ and subjected to extraction without drying.

\section{Materials and reagents}

Methanol, chloroform, $80 \%$ acetic acid (all of analytical reagent grade), and acetonitrile (HPLC grade) were purchased from the Polish Chemical Plant POCh (Gliwice, Poland). 2,2'-azinobis(3-ethylbenzothiazoline-6-sulfonic acid) diammonium salt (ABTS), 2,2'-diphenylpicrylhydrazyl (DPPH), di-potassium peroxydisulfate, linoleic acid, Tween 20 , and $\beta$-carotene were purchased from Sigma-Aldrich (Poznań, Poland). Water was purified on a Milli-Q system from Millipore (Millipore, Bedford, MA, USA). Sand was obtained as a gift from glassworks (fraction 0.4-0.6 mm). The standard of quercetin was purchased from Merck (Darmstadt, Germany).

During the experiments, there were applied the following pathogenic fungi: Alternaria alternate (Fries) Keissler, Fusarium culmorum (Smith) Saccardo, Rhizoctonia solani Kuhn, Botrytis cinerea Persoon, Phytophthora infestans, anamorph, and the fungus causing ascosphaeriosis in bees: Ascosphaera apis ATCC 13785. A. apis was supplied by the American Type Culture Collection (ATCC, USA). The plant pathogenic fungi were obtained from the Department of Phytopathology and Entomology, University of Warmia and Mazury in Olsztyn, Poland. P. infestans strain isolated from tomato was provided by the Main Inspectorate of Plant Health and Seed Inspection in Torun (Poland).

\section{Pressurized hot water extraction}

Extractions were performed in a dynamic mode using the hand-made PHWE system described in detail in [18] on weighed portions of onion scales $(0.5 \mathrm{~g})$ which were mixed with sand and placed into the extraction vessels, sequentially connected to the extraction system.

The effect of extraction temperature $\left(X_{1}\right)$, pressure $\left(X_{2}\right)$, and flow of extracting medium $\left(X_{3}\right)$ on the PHWE recovery was examined in the range of $50-175^{\circ} \mathrm{C}, 40-200 \mathrm{bar}$, and $0.5-3.0 \mathrm{~mL} / \mathrm{min}$, respectively. The collected extracts were transferred into $50 \mathrm{~mL}$ laboratory flasks and filled up to their volume wit with water. Each extraction procedure was repeated three times using fresh portions of plant material.

\section{HPLC analysis}

HPLC measurements were performed with a Dionex liquid chromatograph DX600 (Dionex Corp., Sunnyvale, CA, USA) described in detail in the previous papers $[5,16]$. The identification of the quercetin peak was made comparing the retention time of the peak and its UV-Vis spectra with that of the quercetin standard. The retention time of quercetin was $10.7 \mathrm{~min}$. The quercetin concentrations in the resulting extracts were calculated from the calibration curve which was constructed using six methanolic solutions of quercetin standard in the concentration range $1.44-144 \mu \mathrm{g} / \mathrm{mL}$.

\section{Antioxidant activity}

The antioxidant activity of extracts obtained under the optimal PHWE conditions was assessed using the three spectrophotometric methods presented below. All measurements were performed using the UV Probe-2550 Spectrophotometer (Shimadzu, Kyoto, Japan). 


\section{$\beta$-carotene bleaching assay}

The test was performed according to the method described in [19]. Briefly, $25 \mu \mathrm{L}$ of linoleic acid, $185 \mu \mathrm{L}$ of Tween $20(200 \mathrm{mg})$, and $5 \mathrm{~mL}$ of $\beta$-carotene solution $(0.5 \mathrm{mg}$ of $\beta$-carotene in $1 \mathrm{~mL}$ of chloroform) were used for the preparation of the stock solution of $\beta$-carotene/linoleic acid emulsion in water. After evaporation of chloroform, the residue was dispersed in $100 \mathrm{~mL}$ of distilled water which was saturated with oxygen $(t=30 \mathrm{~min}, F=100 \mathrm{~mL} / \mathrm{min})$. The mixture was vigorously shaken and $2900 \mu \mathrm{L}$ of $\beta$-carotene/ linoleic acid emulsion in water was mixed with $100 \mu \mathrm{L}$ of the PHWE extract. Then, the whole mixture was placed in an optical glass cuvette $(1 \mathrm{~cm} \times 1 \mathrm{~cm} \times 3.5 \mathrm{~cm})$ which was stoppered tightly and set in a water bath $\left(45^{\circ} \mathrm{C}\right)$. The decrease of $\beta$-carotene absorbance was monitored at $470 \mathrm{~nm}$ in subsequent intervals (10 min) until orange color of the control sample disappeared (about $180 \mathrm{~min}$ ). The control sample was prepared mixing $2900 \mu \mathrm{L}$ of $\beta$-carotene emulsion with $100 \mu \mathrm{L}$ of water. To zero the spectrophotometer, the $\beta$-carotene free emulsion with water was prepared. The antioxidant activity was calculated as the inhibition percentage relative to the control.

\section{DPPH method}

$2900 \mu \mathrm{L}$ of $\mathrm{DPPH}^{\bullet}$ methanolic solution (initial absorbance $0.7 \pm 0.05$ at $516 \mathrm{~nm}$ ) was mixed with $100 \mu \mathrm{L}$ of PHWE extract in a $4 \mathrm{~mL}$ test tube [20]. The whole was vigorously shaken for $30 \mathrm{~s}$, then poured into an optical glass cuvette $(1 \mathrm{~cm} \times 1 \mathrm{~cm} \times 3.5 \mathrm{~cm})$, and placed in a spectrophotometer. The changes of DPPH radical were monitored at $516 \mathrm{~nm}$ in a continuous manner for $60 \mathrm{~min}$ with a spectrophotometer. Methanol with water was used to zero the spectrophotometer.

\section{ABTS method}

The determination was made in accordance with [21]. To prepare the cationic radical $\mathrm{ABTS}\left(\mathrm{ABTS}^{\bullet+}\right), 5 \mathrm{~mL}$ of a $7 \mathrm{mM}$ aqueous ABTS solution was mixed with $88 \mathrm{~mL}$ of $140 \mathrm{mM}$ potassium persulfate $\left(\mathrm{K}_{2} \mathrm{~S}_{2} \mathrm{O}_{8}\right)$. The resulting solution was incubated for $16 \mathrm{~h}$ in the dark and then diluted with methanol to an absorbance value of $0.7 \pm 0.05$ at $744 \mathrm{~nm}$. During the measurements, $2900 \mu \mathrm{L}$ of the methanolic ABTS radical solution was mixed in a $4 \mathrm{~mL}$ test tube with $100 \mu \mathrm{L}$ of PHWE extracts. Pure methanol and water was used to zero the spectrophotometer. The percentage of ABTS ${ }^{\bullet+}$ inhibition was calculated analogously to $\mathrm{DPPH}^{\bullet}$.

\section{Antifungal activity}

The activities of the extracts against $B$. cinerea, $F$. culmorum, $R$. solani, A. alternate, $P$. infestans, and A. apis were tested in vitro using acetone solutions of dry extracts (concentration $20.0 \mathrm{mg} / \mathrm{mL}$ ) and the procedure described elsewhere [22]. Briefly, a $1 \mathrm{~mL}$ aliquot of the solution was evenly spread over the surface of Sabouraud dextrose agar, acetone was allowed to evaporate aseptically, and then, $5 \mathrm{~mm}$ mycelial discs were cut from a homogeneous fungus culture and placed on the agar medium surface. The plates with only acetone deposited on the agar medium were used as a negative control. All plates were incubated at $25^{\circ} \mathrm{C}$ for 5 days. Activity was determined by measuring the inhibitory zone diameter of the mycelium on the treatment dish against the colony diameter of the mycelium on the control dish. The test was carried out in six replications.

\section{Experimental design and statistical analysis}

A statistical experimental based on Central Composite Design and Statistica10 software (StaSoft, Inc., USA) were used to determine the effect of three independent variables and the optimum conditions of quercetin extraction. The process and response variables were determined from the published data obtained for alcoholic and aqueous-alcoholic extractants $[5,7-10,17]$. The effect of the variables temperature, pressure, and the flow velocity of the extraction medium coded as $X_{1}, X_{2}$, and $X_{3}$ was investigated at five levels $(-1.68179,-1,0,1,1.68179)$. The dependent variable was $Y$, i.e., as large as possible the quercetin yield from $1 \mathrm{~g}$ of onion scales. The validity of the model was evaluated through the analysis of variance (ANOVA), the determination coefficient $\left(R^{2}\right)$, and the adjusted determination coefficient $\left(R_{\text {adj }}^{2}\right)$. In addition, the optimal condition was verified by conducting experiments under these conditions.

All experimental data are presented as mean values of three (in the case of antifungal studies of six) independent measurements $\pm \mathrm{SD}$. The relative standard deviation (RSD) of all biological measurements was lower than $10 \% . P<0.05$ was used to declare the statistically significant terms with 95\% confidence level.

\section{Results and discussion}

\section{Extraction optimization}

Table 1 presents the layout of the Central Composite Design (CCD) with the decoded independent variables and the experimental values of the quercetin yield obtained under the given PHWE extraction conditions of white and red onion scales, together with the values predicted from the "main linear/quadratic effects and 2-way interactions" model. The CCD applied connected the vertices of the hypercube, the coordinates of which were given by the standard $2^{\mathrm{n}}$ design. 
Table 1 Central Composite Design arrangement, responses, and predicted values for the quercetin yield from the white and red onion scales

\begin{tabular}{|c|c|c|c|c|c|c|c|}
\hline \multirow[t]{3}{*}{ Run } & \multicolumn{3}{|c|}{ Independent variables } & \multicolumn{4}{|c|}{ Quercetin yield (Y). mg/g } \\
\hline & \multirow{2}{*}{$\begin{array}{l}\text { Temperature } \\
X_{1}\end{array}$} & \multirow{2}{*}{$\begin{array}{l}\text { Pressure } \\
X_{2}\end{array}$} & \multirow{2}{*}{$\begin{array}{l}\text { Flow } \\
X_{3}\end{array}$} & \multicolumn{2}{|c|}{ White onion scales } & \multicolumn{2}{|c|}{ Red onion scales } \\
\hline & & & & Experimental & Predicted & Experimental & Predicted \\
\hline 1 & 50 & 40 & 0.5 & 10.61 & 11.37 & 14.02 & 15.06 \\
\hline 2 & 50 & 40 & 1.5 & 17.08 & 16.80 & 18.45 & 16.41 \\
\hline 3 & 50 & 40 & 3.0 & 7.14 & 7.48 & 11.96 & 12.23 \\
\hline 4 & 50 & 100 & 0.5 & 17.06 & 17.21 & 16.43 & 18.03 \\
\hline 5 & 50 & 100 & 1.5 & 22.73 & 22.86 & 19.94 & 19.38 \\
\hline 6 & 50 & 100 & 3.0 & 14.79 & 13.89 & 14.46 & 15.21 \\
\hline 7 & 50 & 200 & 0.5 & 12.55 & 11.93 & 18.40 & 18.68 \\
\hline 8 & 50 & 200 & 1.5 & 18.03 & 17.97 & 21.20 & 20.04 \\
\hline 9 & 50 & 200 & 3.0 & 9.08 & 9.57 & 16.05 & 15.87 \\
\hline 10 & 125 & 40 & 0.5 & 29.15 & 28.82 & 28.33 & 29.16 \\
\hline 11 & 125 & 40 & 1.5 & 34.62 & 34.18 & 29.56 & 30.87 \\
\hline 12 & 125 & 40 & 3.0 & 24.68 & 24.77 & 27.56 & 27.24 \\
\hline 13 & 125 & 100 & 0.5 & 34.60 & 34.65 & 34.93 & 31.32 \\
\hline 14 & 125 & 100 & 1.5 & 40.28 & 40.25 & 35.16 & 33.04 \\
\hline 15 & 125 & 100 & 3.0 & 31.83 & 31.18 & 28.13 & 29.41 \\
\hline 16 & 125 & 200 & 0.5 & 29.10 & 29.39 & 30.55 & 30.63 \\
\hline 17 & 125 & 200 & 1.5 & 35.57 & 35.36 & 29.78 & 32.36 \\
\hline 18 & 125 & 200 & 3.0 & 25.63 & 26.86 & 28.77 & 28.73 \\
\hline 19 & 175 & 40 & 0.5 & 18.39 & 17.62 & 27.18 & 26.75 \\
\hline 20 & 175 & 40 & 1.5 & 22.86 & 22.94 & 28.41 & 28.71 \\
\hline 21 & 175 & 40 & 3.0 & 12.92 & 13.47 & 26.40 & 25.44 \\
\hline 22 & 175 & 100 & 0.5 & 22.84 & 23.46 & 27.56 & 28.38 \\
\hline 23 & 175 & 100 & 1.5 & 28.51 & 29.01 & 28.79 & 30.34 \\
\hline 24 & 175 & 100 & 3.0 & 19.72 & 19.88 & 26.78 & 27.07 \\
\hline 25 & 175 & 200 & 0.5 & 18.33 & 18.19 & 27.39 & 26.79 \\
\hline 26 & 175 & 200 & 1.5 & 23.81 & 24.12 & 28.62 & 28.75 \\
\hline 27 & 175 & 200 & 3.0 & 16.87 & 15.56 & 26.61 & 25.50 \\
\hline
\end{tabular}

As results from Table 1, the experimental quercetin yield varied from 7.14 to $40.28 \mathrm{mg} / \mathrm{g}$ for white onion scales and from 11.96 to $35.16 \mathrm{mg} / \mathrm{g}$ for red onion scales. For comparison, the yields of quercetin obtained using organic or water-organic extractants available in the literature range from 13.93 to $28.5 \mathrm{mg} / \mathrm{g}$ [5, 8, 23]. The predicted values were determined using the response surface methodology and empirical relationships between the quercetin yield $(Y)$ and independent variables, i.e., extraction temperature $\left(X_{1}\right)$, pressure $\left(X_{2}\right)$, and flow velocity of the extraction medium $\left(X_{3}\right)$, based on the following equations in the coded units

$$
\begin{aligned}
Y_{W}= & -36.8786+0.8722 X_{1}-0.0036 X_{1}^{2} \\
& +0.2266 X_{2}-0.0010 X_{2}^{2}+14.6273 X_{3}-4.6547 X_{3}^{2} \\
& +0.0001 X_{1} X_{2}-0.0008 X_{1} X_{3}+0.0038 X_{2} X_{3}
\end{aligned}
$$

$$
\begin{aligned}
Y_{R}= & -11.3614+0.5234 X_{1}-0.0019 X_{1}^{2} \\
& +0.0961 X_{2}-0.0003 X_{2}^{2}+4.4168 X_{3} \\
& -1.6546 X_{3}^{2}+0.0002 X_{1} X_{2}-0.0048 X_{1} X_{3} \\
& +0.0001 X_{2} X_{3} .
\end{aligned}
$$

Equation 1 shows the relationship obtained for white onion scales, and Eq. 2 for red onion scales.

To assess the quality of matching the mathematical model to the experimental data, there were used ANOVA and Fisher's $F$ test at the 95\% confidence level as well as the coefficient of determination $\left(R^{2}\right)$ along with the adjusted determination coefficient $\left(R_{\mathrm{adj}}{ }^{2}\right)$. For clarity, a high $F$ value and a low $P$ value indicate the statistical significance of the model. The closer the $R^{2}$ value to 1 , the better the correlation between the predicted and experimental data. All these results are collected in Table 2.

Comparing the calculated $F$ values (see Table 2) with the tabulated value, taking into account the respective degrees 
Table 2 Analysis of variance for the second-order polynomial model estimated for the quercetin yield obtained from the white and red onion scales using PHWE

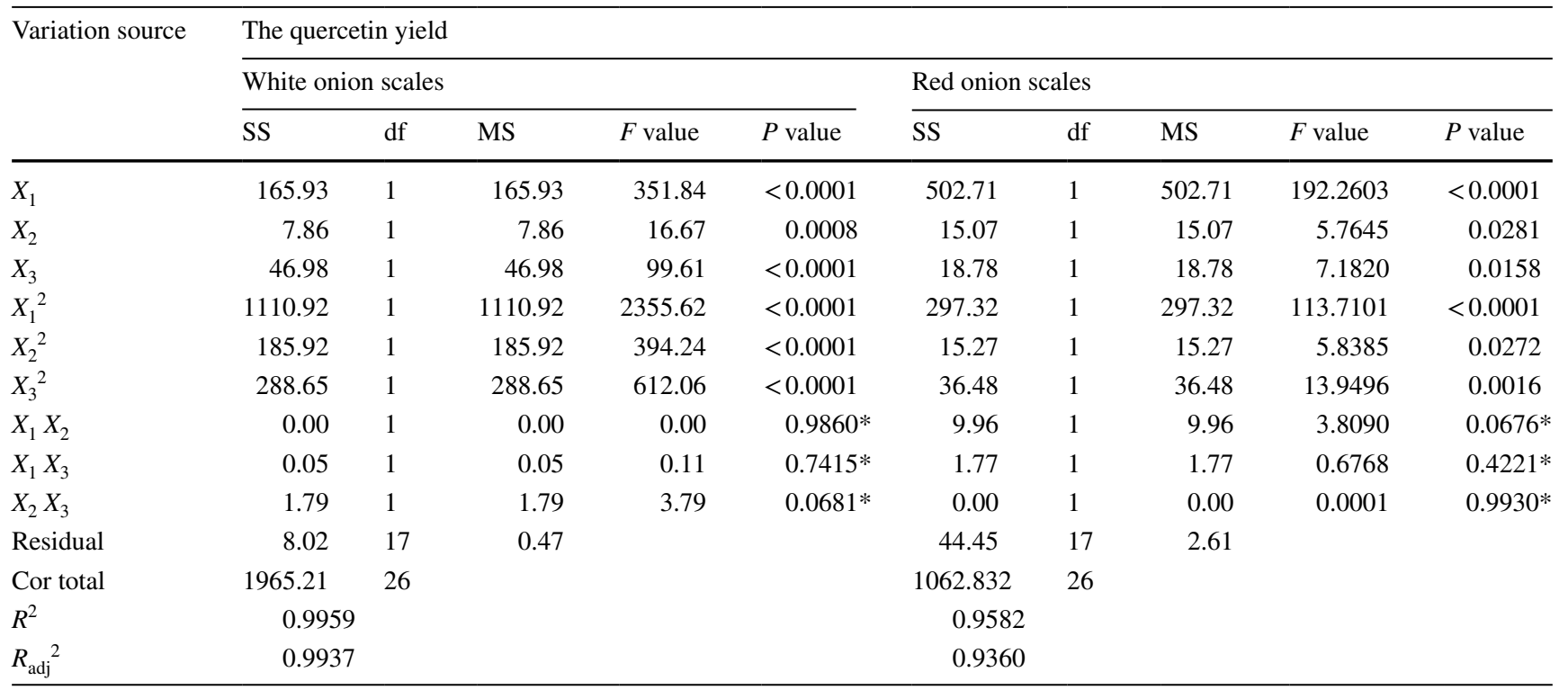

$S S$ sum of square, $d f$ degree of freedom, $M S$ mean square

*Not significant

of freedom, the calculated $F$ values exceed the tabulated $F$ value $\left(F_{(9,7)}=3.67\right)$, which indicates the statistical significance of each parameter. In particular, the temperature turned out to be a very important parameter $(P<0.0001)$ at linear and quadratic terms of both models. The two-way interactions in both models turned out to be statistically insignificant. When ordering the other two parameters on the basis of the calculated $F$ values, it should be stated that in both models, the flow of the extraction medium has a greater impact on the quercetin yield than the pressure. Nevertheless, both parameters are statistically more significant in the model describing the quercetin yield from the white onion than from the red onion (compare the $P$ values for both models).

The analysis of $R^{2}$ values for both models leads to a similar conclusion. The former $R^{2}$ was 0.9959 , and the latter $R^{2}$ was 0.9582 which indicates that the mathematical models could provide $99.59 \%$ and $95.82 \%$ of the results, respectively. The analysis of the $R_{\mathrm{adj}}{ }^{2}$ value, which is a measure for testing the goodness-of-fit of the regression equation, shows that only $0.63 \%$ and $6.44 \%$ of the total variation, respectively, were not explained by the models. Therefore, there is no statistical evidence to suggest that the models do not adequately explain the differentiation of the quercetin yield from white and red onion scales as a function of the variable extraction parameters, i.e., temperature, pressure, and flow velocity of the extraction medium. Therefore, the statistical analysis reveals the adequacy of the models.

\section{Variables affecting PHWE}

Figure 1 shows a more understandable comparison between the linear, quadratic, and 2-way interaction effects of the independent variables with the dependent one, in the form of 3D surface plots. They were obtained by differentiating the two independent variables while keeping the third variable constant and predicting the response. Figure 1A shows the effect of pressure and temperature on the quercetin yield from white onion scales at a flow of $1.6 \mathrm{~mL} / \mathrm{min}$, and Fig. 1B shows the effect of flow and temperature at a pressure of 124.2 bar for the same matrix. In turn, Fig. 1C and D shows the analogous relationships obtained for red onion scales at the flow and pressure equal to $1.5 \mathrm{~mL} / \mathrm{min}$ and $134.2 \mathrm{bar}$, respectively.

Comparing the dependencies presented in Fig. 1, it can be seen that the temperature is the main parameter differentiating the efficiency of quercetin extraction from both types of scales. Its increase in the range of $80-160^{\circ} \mathrm{C}$ for white onions and $80-180{ }^{\circ} \mathrm{C}$ for red onions clearly contributes to the higher extraction efficiency of this compound. However, while in the case of the first matrix, the optimal extraction temperature is at $119^{\circ} \mathrm{C}$, in the case of the red matrix, the optimal extraction temperature is $134^{\circ} \mathrm{C}$. At this point, it should be remembered that the quercetin in onion occurs not only in a free (aglycone) form but also in a bound form, in the form of numerous glycosidic derivatives that are hydrolytically and thermally unstable [2,24]. Red onion compared to white onion, apart from the obvious presence of anthocyanins, is characterized by a different amount of 

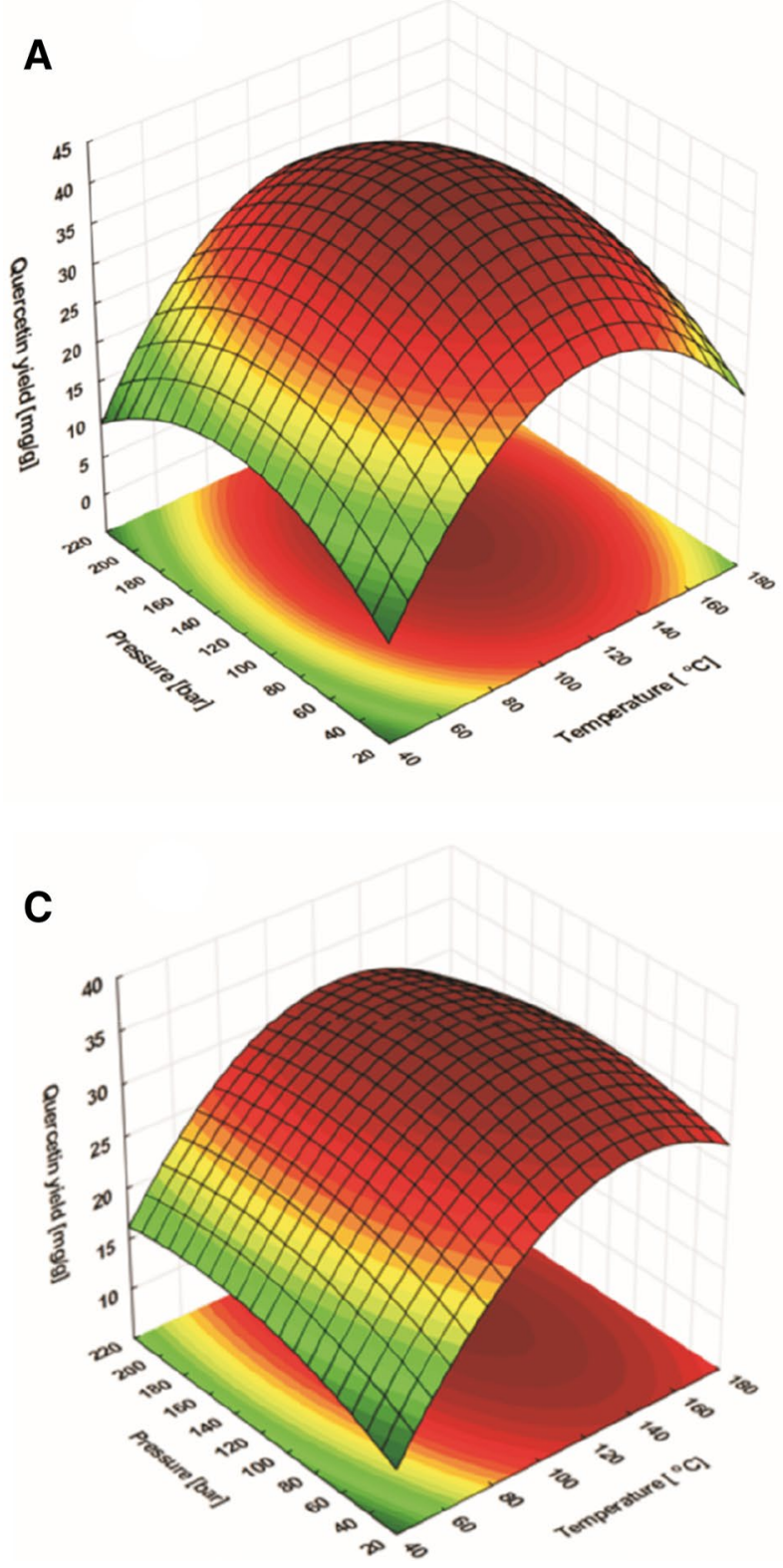

Fig. 1 3D surface plots and contour maps for the quercetin yield obtained from the white onion scales (1) as a function of temperature and pressure $(\mathbf{A})$ and temperature and flow $(\mathbf{B})$, and from the red

glycoside derivatives [2]. Therefore, the observed higher optimal extraction temperature in the case of this matrix may indicate optimal conditions for the degradation of the quercetin derivatives. The validity of this conclusion is confirmed by the results of studies published in $[5,17]$ showing the greater susceptibility of quercetin-4'-glucoside in red onion to hydrolytic degradation and the effect of temperature stress on the increase in degradation of quercetin glycosides under the PLE conditions. This conclusion is supported also by the results discussed in [16], showing that the glycoside forms of hydroxyanthraquinones during their extraction
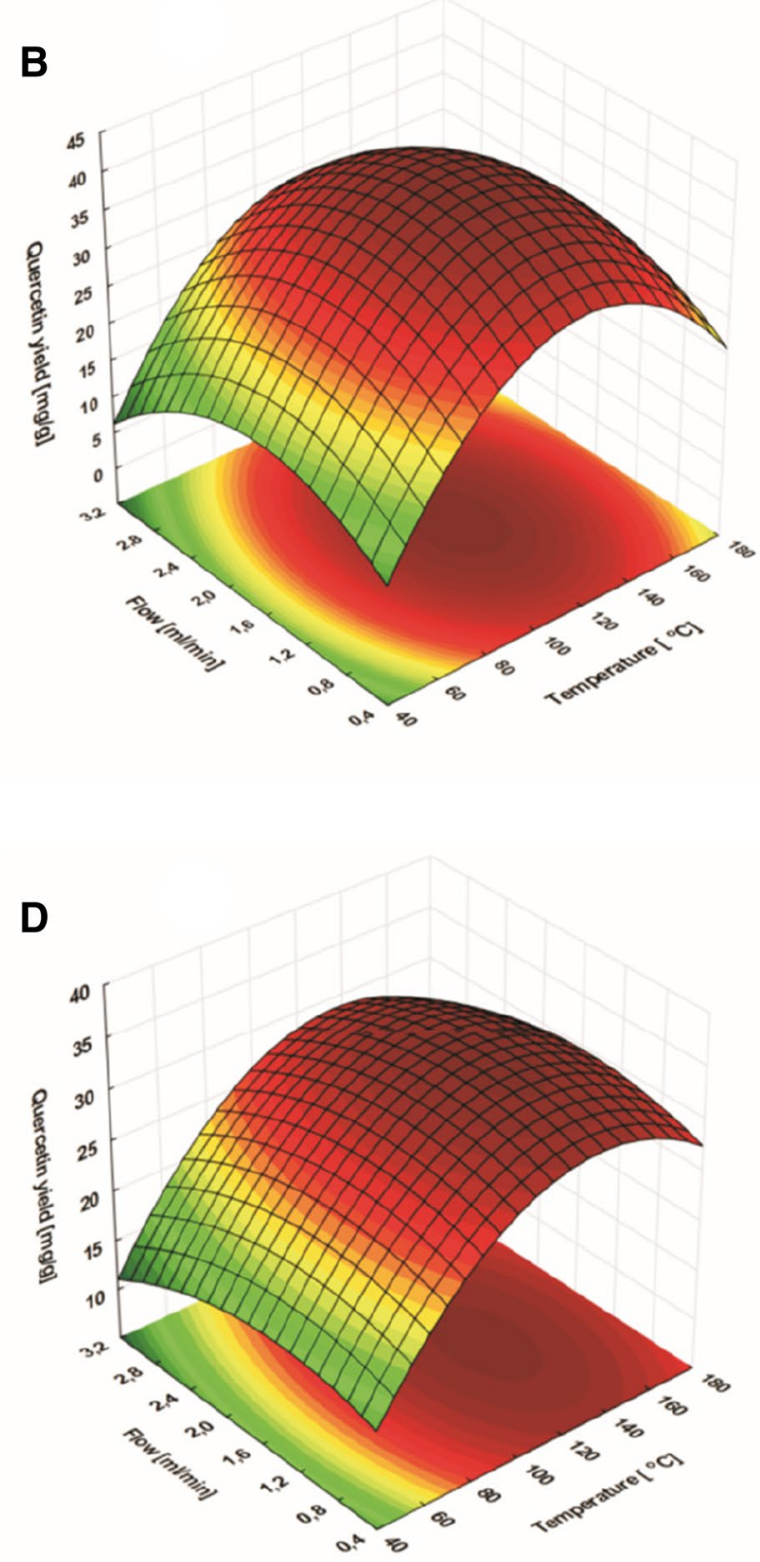

onion scales (2) as a function of temperature and pressure (C) and temperature and flow (D), using PHWE

from the Rumex crispus L. root are easily transformed to the corresponding aglycones when the water content in the extraction mixture and the extraction temperature increase. Nevertheless, a further increase in the extraction temperature to $175{ }^{\circ} \mathrm{C}$ for both matrices leads to reduction of quercetin amount which can be explained by thermal degradation of the compound.

As for the other PHWE parameters, their effect depends on the type of matrix and is generally greater for white onion scales. For this matrix, there is a clear quadratic effect of both extraction pressure and flow velocity of the extraction 

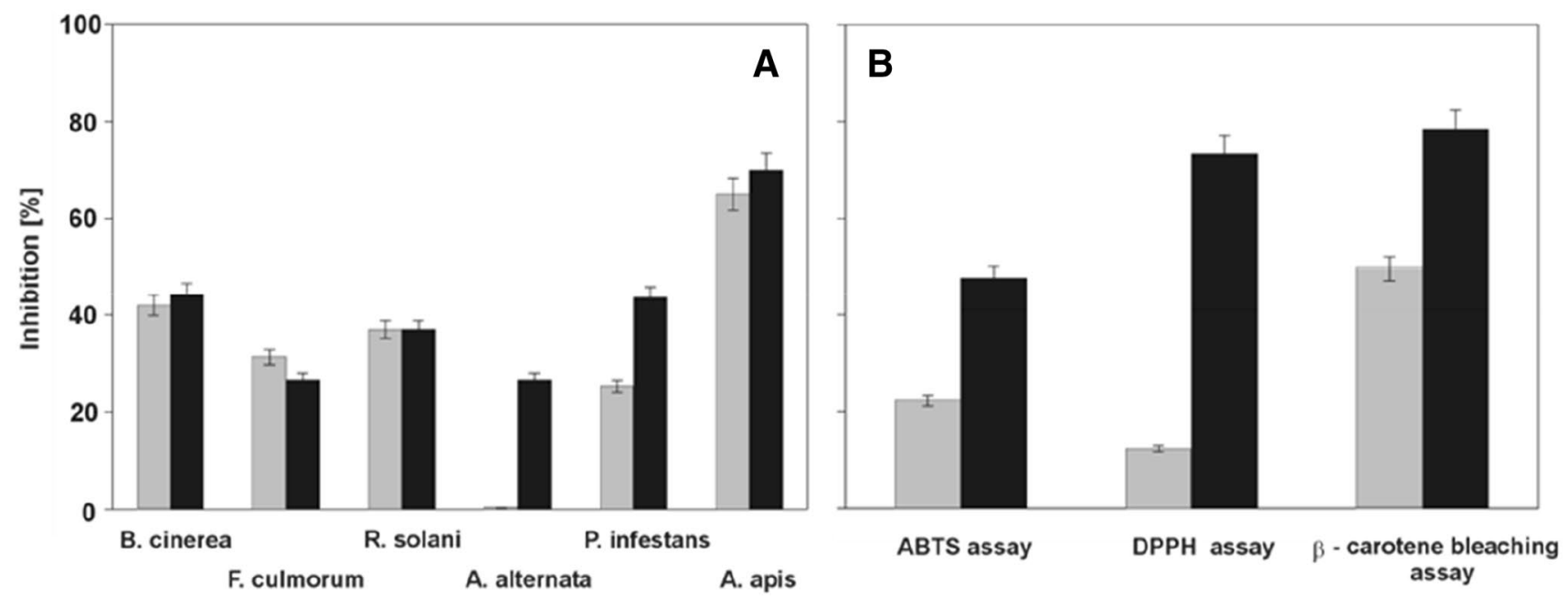

Fig. 2 Antifungal (A) and antioxidant (B) activities of quercetin-rich isolates obtained under the optimized conditions from the white and red onion husks (gray and black bars, respectively) assessed against different fungi and using different approaches

medium (see Fig. 1A and B), and the optimal values are $124.2 \mathrm{bar}$ and $1.6 \mathrm{~mL} / \mathrm{min}$, respectively. In the case of red onions, the optimal values of these parameters are 134.2 bar and $1.5 \mathrm{~mL} / \mathrm{min}$, respectively. The slower the extraction medium flow, the higher the degradation of quercetin glycosides and therefore, the higher the yield of red onion quercetin.

\section{Verification of models}

The suitability of the models for predicting the optimal quercetin yield was tested by comparing the yield predicted by the model with the experimental values determined under the adjusted extraction conditions, i.e., $119^{\circ} \mathrm{C}, 124 \mathrm{bar}$, and $1.6 \mathrm{~mL} / \mathrm{min}$ for white onion scales and $134{ }^{\circ} \mathrm{C}, 134 \mathrm{bar}$, and $1.5 \mathrm{~mL} / \mathrm{min}$ for red onion scales. The quercetin yield predicted by the model under the given extraction conditions was $44.14 \mathrm{mg} / \mathrm{g}$ for white onion scales and $33.57 \mathrm{mg} / \mathrm{g}$ for red ones. The determined experimental values were $45.54 \pm 2.93 \mathrm{mg} / \mathrm{g}$ and $33.31 \pm 1.94 \mathrm{mg} / \mathrm{g}$, respectively. The ANOVA analysis confirmed no statistically significant differences between the values obtained experimentally and those predicted by the model (for both varieties, the calculated $F$ values were lower than the tabulated $F$ value). Therefore, it can be assumed that the designed model explains the real process of quercetin extraction from both onion varieties.

\section{Biological activity}

To prove a wide range of possible biological activity of quercetin-rich isolates obtained from the onion waste materials under the optimized extraction conditions, they were assessed for antioxidant and antifungal activities. The antioxidant activity was examined by the DPPH, ABTS, and $\beta$-carotene methods. The antifungal activity was tested against various plant pathogenic fungi, such $B$. cinerea, $F$. culmorum, $R$. solani, A. alternate, and $P$. infestans as well as against the bees pathogenic fungi (A. apis). The results of these experiments, expressed as the inhibition percent (I $\%$ ), are shown in Fig. 2.

The data presented in Fig. 2 confirm the biological activity of the obtained extracts and the fact that this is the onion variety that modifies their biological activity. The extent of this modification depends on both the type of pathogen and the method used to evaluate the antioxidant activity (compare Fig. 2A and B). While in the case of $R$. solani, B. cinerea, and A. apis, there is no statistically significant difference in the inhibition of mycelium growth caused by the extracts from scales of both onion cultivars $\left(F_{\text {exp }}<F_{c r i t}\right)$, in the case of $P$. infestans and $A$. alternata, the inhibition of red onion scales extract exceeds that of the white variety extract $\left(F_{\text {exp }}>>F_{\text {crit }}\right)$. In turn, the growth inhibition of F. culmorum is more effective after the use of white onion scales extract $\left(F_{\text {exp }}>F_{c r i t}\right)$. It is also worth noting that $A$. alternata exhibits sensitivity to the red onion extract while being completely resistant to the white onion one. This result is surprising, considering that both extracts have a similar amount of quercetin. Evidently other components of the extract differentiate the inhibition of this fungus.

As for the antioxidant activity of the extracts (see Fig. 2B), the greatest activity (the highest value of inhibition percent) is shown by the $\beta$-carotene bleaching assay. In turn, the smallest one is revealed by the DPPH method. It may be related to the environment of the neutralization reaction itself, since scavenging of the peroxide radical in the B-carotene assay takes place in the emulsion of water which 
is also the extraction medium. Regardless of the method, the red onion scales' extracts show a greater antioxidant activity than the white ones. This can be explained by different contents of polyphenolic compounds in the examined matrices $[2,25]$.

\section{Conclusions}

The annual world onion production is over 80 million tons. Onion scales are the main wastes from its production. There have not been largely applied so far. However, this material has the potential to be used for the production of functional isolates, including functional food additives, as long as the resulting product meets the generally recognized as safe (GRAS) criteria.

In this study, to increase the content of quercetin in the isolates obtained from onion scales, in accordance with the zero waste philosophy, using water as an environmentally and health-friendly extractant belonging to the GRAS solvents, a mathematical model was constructed based on the Central Composite Design. The applicability of the model was found comparing the efficiency of quercetin extraction predicted by the model with the experimental values determined under the adjusted extraction conditions, obtaining good agreement and high quercetin content. When assessing the biological activity of isolates obtained under the improved extraction conditions, it was shown that these properties are so significant that they should encourage the use of this raw material, previously treated as worthless waste, for the production of various functional materials with antioxidant and antifungal properties.

Funding The authors did not receive support from any organization for the submitted work

\section{Declarations}

Conflict of interest The authors report no conflict of interest.

Compliance with ethics requirements This article does not contain any studies with human participants or animals performed by any of the authors.

Open Access This article is licensed under a Creative Commons Attribution 4.0 International License, which permits use, sharing, adaptation, distribution and reproduction in any medium or format, as long as you give appropriate credit to the original author(s) and the source, provide a link to the Creative Commons licence, and indicate if changes were made. The images or other third party material in this article are included in the article's Creative Commons licence, unless indicated otherwise in a credit line to the material. If material is not included in the article's Creative Commons licence and your intended use is not permitted by statutory regulation or exceeds the permitted use, you will need to obtain permission directly from the copyright holder. To view a copy of this licence, visit http://creativecommons.org/licenses/by/4.0/.

\section{References}

1. Slimestad R, Fossen T, Vågen IM (2007) Onions: a source of unique dietary flavonoids. J Agric Food Chem. https://doi.org/10. 1021/jf0712503

2. Sharma K, Ko EY, Assefa AD, Ha S, Nile SH, Lee ET, Park SW (2015) Temperature-dependent studies on the total phenolics, flavonoids, antioxidant activities, and sugar content in six onion varieties. J Food Drug Anal. https://doi.org/10.1016/j.jfda.2014. 10.005

3. Anand David AV, Arulmoli R, Parasuraman S (2016) Overviews of biological importance of quercetin: a bioactive flavonoid. Pharmacogn Rev. https://doi.org/10.4103/0973-7847.194044

4. El-Saber Batiha G, Beshbishy AM, Ikram M, Mulla ZS, Abd ElHack ME, Taha AE, Algammal AM, Ali Elewa YH (2020) The pharmacological activity, biochemical properties, and pharmacokinetics of the major natural polyphenolic flavonoid: quercetin. Foods. https://doi.org/10.3390/foods9030374

5. Wianowska D (2015) Application of sea sand disruption method for HPLC determination of quercetin in plants. J Liq Chromatogr Relat Technol. https://doi.org/10.1080/10826076.2015.1012520

6. Wianowska D, Dawidowicz AL, Bernacik K, Typek R (2017) Determining the true content of quercetin and its derivatives in plants employing SSDM and LC-MS analysis. Eur Food Res Technol. https://doi.org/10.1007/s00217-016-2719-8

7. Søltoft M, Christensen JH, Nielsen J, Knuthsen P (2009) Pressurised liquid extraction of flavonoids in onions. Method development and validation. Talanta. https://doi.org/10.1016/j.talanta. 2009.06.073

8. Ko M-J, Cheigh C-I, Cho S-W, Chung M-S (2011) Subcritical water extraction of flavonol quercetin from onion skin. J Food Eng. https://doi.org/10.1016/j.jfoodeng.2010.09.008

9. Dmitrienko SG, Kudrinskaya VA, Apyari VV (2012) Methods of extraction, preconcentration, and determination of quercetin. J Anal Chem. https://doi.org/10.1134/S106193481204003X

10. Lee KA, Kim KT, Kim HJ, Chung MS, Chang PS, Park H, Pai HD (2014) Antioxidant activities of onion (Allium cepa L.) peel extracts produced by ethanol, hot water, and subcritical water extraction. Food Sci Biotechnol. https://doi.org/10.1007/ s10068-014-0084-6

11. Zill-E-Huma VMA, Fabiano-Tixier AS, Elmaataoui M, Dangles $O$, Chemat $F(2011)$ A remarkable influence of microwave extraction: enhancement of antioxidant activity of extracted onion varieties. Food Chem. https://doi.org/10.1016/j.foodchem.2011.01.112

12. Jang M, Asnin L, Nile SH, Keum YS, Kim HY, Park SW (2013) Ultrasound-assisted extraction of quercetin from onion solid wastes. Int J Food Sci Technol. https://doi.org/10.1111/j.13652621.2012.03180.x

13. Katsampa P, Valsamedou E, Grigorakis S, Makris DP (2015) A green ultrasound-assisted extraction process for the recovery of antioxidant polyphenols and pigments from onion solid wastes using Box-Behnken experimental design and kinetics. Ind Crops Prod. https://doi.org/10.1016/j.indcrop.2015.09.039

14. Ameer K, Shahbaz HM, Kwon J-H (2017) Green extraction methods for polyphenols from plant matrices and their byproducts: a review. Compr Rev Food Sci Food Saf. https://doi.org/10.1111/ 1541-4337.12253

15. Wianowska D, Gil M (2019) Critical approach to PLE technique application in the analysis of secondary metabolites in plants. 
TrAC Trends Anal Chem. https://doi.org/10.1016/j.trac.2019.03. 018

16. Wianowska D (2014) Hydrolytical instability of hydroxyanthraquinone glycosides in pressurized liquid extraction. Anal Bioanal Chem. https://doi.org/10.1007/s00216-014-7744-5

17. Wianowska D, Dawidowicz AL (2016) Effect of water content in extraction mixture on the pressurized liquid extraction efficiency - stability of Quercetin 4'-glucoside during extraction from onions. J AOAC Int. https://doi.org/10.5740/jaoacint.16-0019

18. Dawidowicz AL, Rado E, Wianowska D (2009) Static and dynamic superheated water extraction of essential oil components from Thymus vulgaris L. J Sep Sci. https://doi.org/10.1002/jssc. 200900214

19. Dawidowicz AL, Olszowy M (2015) Depletion/protection of $\beta$-carotene in estimating antioxidant activity by $\beta$-carotene bleaching assay. J Food Sci Technol. https://doi.org/10.1007/ s13197-015-1820-5

20. Dawidowicz AL, Wianowska D, Olszowy M (2012) On practical problems in estimation of antioxidant activity of compounds by DPPH method (Problems in estimation of antioxidant activity). Food Chem. https://doi.org/10.1016/j.foodchem.2011.09.067

21. Nenadis N, Wang LF, Tsimidou M, Zhang HY (2004) Estimation of scavenging activity of phenolic compounds using the ABTS. + assay. J Agric Food Chem. https://doi.org/10.1021/jf0400056
22. Wianowska D, Garbaczewska S, Cieniecka-Roslonkiewicz A, Dawidowicz AL, Typek R, Kielczewska A (2020) Influence of the extraction conditions on the antifungal properties of walnut green husk isolates. Anal Lett. https://doi.org/10.1080/00032719. 2020.1725889

23. Savic-Gajic IM, Savic IM, Nikolic VD (2018) Modelling and optimization of quercetin extraction and biological activity of quercetin-rich red onion skin extract from Southeastern Serbia. J Food Nutr Res 57:15-26

24. Roldán-Marín E, Sánchez-Moreno C, Lloría R, de Ancos B, Cano MP (2009) Onion high-pressure processing: flavonol content and antioxidant activity. LWT Food Sci Technol. https://doi.org/10. 1016/j.lwt.2008.11.013

25. Rodrigues AS, Pérez-Gregorio MR, García-Falcón MS, SimalGándara J (2009) Effect of curing and cooking on flavonols and anthocyanins in traditional varieties of onion bulbs. Food Res Int. https://doi.org/10.1016/j.foodres.2009.04.005

Publisher's Note Springer Nature remains neutral with regard to jurisdictional claims in published maps and institutional affiliations. 